\title{
Prevalence of infection and 18S rRNA gene sequences of Cytauxzoon species in Iberian lynx (Lynx pardinus) in Spain
}

\author{
J. MILLÁN ${ }^{1 *}$, V. NARANJO², A. RODRÍGUEZ ${ }^{1}$, J. M. PÉREZ DE LA LASTRA², \\ A. J. MANGOLD ${ }^{3}$ and J. DE LA FUENTE ${ }^{2,4}$ \\ ${ }^{1}$ Department of Conservation Biology, Estación Biológica de Doñana (CSIC), Pabellón del Perú, Avda. María Luisa s/n, \\ 41013-Sevilla, Spain \\ ${ }^{2}$ Instituto de Investigación en Recursos Cinegéticos IREC (CSIC-UCLM-ҰCCM), Ronda de Toledo s/n, 13071-Ciudad Real, \\ Spain \\ ${ }^{3}$ Instituto Nacional de Tecnología Agropecuaria, Estación Experimental Agropecuaria Rafaela, CC 22, CP 2300 Rafaela, \\ Santa Fe, Argentina \\ ${ }^{4}$ Department of Veterinary Pathobiology, Center for Veterinary Health Sciences, Oklahoma State University, Stillwater, \\ OK 74078, USA
}

(Received 14 December 2006; revised 11 Fanuary 2007; accepted 15 Fanuary 2007; first published online 28 February 2007)

\section{SUMMARY}

The Iberian lynx (Lynx pardinus) is the most endangered felid in the world. Only about 160 individuals remain in 2 separate metapopulations in Southern Spain (Sierra Morena and Doñana). We obtained blood samples of 20 lynxes captured from 2004 to 2006, and determined the prevalence of infection and genetic diversity of Cytauxzoon spp. using 18S rRNA PCR and sequence analysis. Prevalence of infection was 15\% (3 of 20). Cytauxzoon sp. was only detected in Sierra Morena. For phylogenetic analysis, we used the sequences reported in the present study and those characterized in different domestic and wild felids and ticks from North and South America, Asia and Europe. Three different Cytauxzoon sp. sequences were obtained. They were closely related to that obtained from a Spanish cat, but diverged in up to $1.0 \%$ with respect to the only previously reported sequence from an Iberian lynx. Conversely, the latter sequence clustered together with $C$. manul sequences obtained from Pallas cats (Otocolobus manul) in Mongolia. Our analysis yields a separate cluster of $C$. felis sequences from cats, wild felids and ticks in the United States and Brazil. These results suggest that at least 2 different Cytauxzoon spp. may be present in Iberian lynx. The apparent absence in one of the areas, together with the possibility of fatal cytauxzoonosis in lynxes makes necessary disease risks to be taken into account in management conservation strategies, such as translocations and re-introductions.

Key words: conservation, Cytauxzoon felis, cytauxzoonosis, endangered species, Lynx pardinus, molecular characterization, piroplasm.

\section{INTRODUCTION}

According to the World Conservation Union, the Iberian lynx (Lynx pardinus) is the most endangered felid in the world (Nowell and Jackson, 1996) with approximately 160 individuals inhabiting 2 separate areas of Southern Spain, namely Sierra Morena and Doñana (Guzmán et al. 2004). Among mammalian predators, felids are especially vulnerable to human action (habitat transformation, road-killing, illegal hunting) and $44 \%$ of the species in this taxon experience serious threats (Nowell and Jackson, 1996). An increasing concern exists about the role of diseases as a threat for conservation of endangered species (Deem et al. 2001; Haydon et al. 2002; Smith

* Corresponding author: Estación Biológica de Doñana (CSIC), Pabellón del Perú, Avda. María Luisa s/n, 41013Sevilla, Spain. Tel: +34 954323240. Fax: +34 954621125. E-mail: syngamustrachea@hotmail.com et al. 2006). It has been shown that diseases could induce extinction of wildlife species (e.g. Thorne and Williams, 1988), especially when their population size is small and reservoir hosts are present in the area (de Castro and Bolker, 2005).

Cytauxzoonosis is a tick-borne disease caused by Cytauxzoon felis, a piroplasm belonging to the family Theileriidae. Its life-cycle in the vertebrate host includes an intra-erythrocytic phase and a tissue phase consisting of large schizonts that develop in macrophages or monocytes. The tissue phase is necessary for the disease to be fatal (Kier and Greene, 1998). The bobcat (Lynx rufus) is considered the natural host of $C$. felis in North America. In this species, $C$. felis causes a persistent, subclinical infection. In contrast, $C$. felis infections in domestic cats are characterized by an acute, highly fatal febrile disease (Kier and Greene, 1998). Cytauxzoon felis was also reported in free-living cougars and Florida panthers (Puma concolor; Rotstein et al. 1999) in 
Table 1. Age and sex-classes of the Iberian lynxes sampled for the detection of Cytauxzoon sp.

(Parasitized animals are given in parentheses.)

\begin{tabular}{llllllll}
\hline \hline & \multicolumn{2}{l}{ Sierra Morena } & & & \multicolumn{2}{l}{ Doñana } \\
\cline { 2 - 4 } \cline { 7 - 8 } & Adult & Subadult & Juvenile & & Adult & Subadult & Juvenile \\
\hline Male & 0 & $3(1)$ & $3(2)$ & & $3(0)$ & $1(0)$ & $1(0)$ \\
Female & 0 & $1(0)$ & $2(0)$ & & $5(0)$ & $1(0)$ & 0 \\
\hline \hline
\end{tabular}

North America. Florida panthers may react to $C$. felis in a way similar to bobcats (Forrester, 1992). A fatal case of cytauxzoonosis was reported in a captive white tiger (Panthera tigris) in the United States (Garner et al. 1996). A closely related piroplasm, C. manul, was reported parasitizing Pallas cats (Otocolobus manul) in Mongolia (Ketz-Riely et al. 2003; Reichard et al. 2005). In Iberian lynx, Luaces et al. (2005) reported the finding of a small intra-erythrocytic piroplasm in a blood film of a juvenile animal from Sierra Morena. 18S rRNA PCR amplification and sequencing revealed similarity to $C$.felis.

The relevance of Cytauxzoon spp. as a threat for Iberian lynx conservation is unknown. The infected lynx reported by Luaces et al. (2005) did not show any sign of disease and haematological and biochemical values were normal. However, although bobcats can develop the tissue phase of the pathogen and may die of experimental cytauxzoonosis (Kier et al. 1982; Blouin et al. 1987), it was considered that $C$. felis could not cause the death of wild bobcats. This view changed when Nietfeld and Pollock (2002) reported a free-living bobcat cub that died of acute cytauxzoonosis. These authors suggested that some bobcats may die each year due to cytauxzoonosis, but these cases remain undetected by current surveillance protocols. It is unknown whether the Iberian lynx experiences a similar situation.

Several questions regarding the aetiology and epidemiology of piroplasmosis in the Iberian lynx emerged from the findings of Luaces et al. (2005). As discussed by Nietfeld and Pollock (2002), factors such as host age and sex, and C.felis strain may play a role in the epidemiology of the disease. Surveillance for monitoring prevalence of a disease in different areas and age classes is the first step for preventing major disease problems in animal populations (Scott, 1988). The retrospective analysis of 50 lynx blood and organ samples (47 from Doñana and 3 from Sierra Morena) revealed no additional positive animal in Doñana (Luaces et al. 2005). Thus, it is currently unknown whether Cytauxzoon is distributed in both populations or is currently confined to Sierra Morena. If the latter is true, disease risks may arise if lynx translocations from Sierra Morena to Doñana are carried out (Mathews et al. 2006). The Cytauxzoon sp. described by Luaces et al. (2005) showed maximum homology with the $18 \mathrm{~S}$ rRNA gene sequence of $C$. manul obtained from a Pallas cat (Ketz-Riely et al. 2003) and with a Cytauxzoon sp. from a Spanish domestic cat (Criado-Fornelio et al. 2004). However, Luaces et al. (2005) reported only 1 infected animal, which precluded the analysis of Cytauxzoon genetic diversity in Iberian lynx. This information may be relevant to correlate genotypes with pathogenicity and evaluate the possible impact of Cytauxzoon infection on wild Iberian lynx endangered populations.

The aim of the present work was to determine by $18 \mathrm{~S}$ rRNA PCR and sequence analysis the observed prevalence of Cytauxzoon spp. in Iberian lynx and to characterize the genetic diversity of this pathogen in the Iberian lynx.

\section{MATERIALS AND METHODS}

\section{Study areas}

The last metapopulations of Iberian lynx persist in Sierra Morena and Doñana, two localities $230 \mathrm{~km}$ apart (Guzmán et al. 2004). Doñana $\left(37^{\circ} 0^{\prime} \mathrm{N}\right.$, $\left.6^{\circ} 30^{\prime} \mathrm{W}\right)$ is a protected, coastal area with sandy soils of marine origin. It is isolated by marshland and farmland from other forest blocks. Sierra Morena $\left(38^{\circ} 13^{\prime} \mathrm{N}, 4^{\circ} 10^{\prime} \mathrm{W}\right)$ is a hilly area with heights up to $1300 \mathrm{~m}$. In both areas Mediterranean scrubland dominates, and climate is Mediterranean subhumid with mild, wet winters and hot, dry summers.

\section{Animals and sample preparation}

Twenty different free-living Iberian lynxes were surveyed, 11 in Doñana and 9 in Sierra Morena (see Table 1 for detailed sex and age-classes), from November 2004 to June 2006. Lynxes were separated into 3 age classes according to Ferreras et al. (2004): juveniles living in the natal area ( $<1$ year old); subadults during the modal natal dispersal period (1-2 years old); and adults ( $>2$ years old). Animals were sampled in 3 seasons, summer (July-August), autumn (November-December) and winter (January-March). Lynxes had to be sampled during captures for incorporations into the Captive Breeding Program, or for radio-collaring, and immobilized 
Table 2. Cytauxzoon species sequences included in the analysis

\begin{tabular}{|c|c|c|c|}
\hline Sequence $^{\mathrm{a}}$ (Reference) & Host & Country & Abbreviation \\
\hline $\begin{array}{l}\text { AF399930 (Meinkoth et al. 2000; } \\
\text { Birkenheuer et al. 2006a) }\end{array}$ & Domestic cat (Felis catus) & USA & DC1 \\
\hline AY531524 (Birkenheuer et al. 2006b) & Domestic cat (Felis catus) & USA & $\mathrm{DC} 2$ \\
\hline AY309956 (Criado-Fornelio et al. 2004) & Domestic cat (Felis catus) & Spain & DC3 \\
\hline Identical to AF399930 (Yabsley et al. 2006) & $\begin{array}{l}\text { Florida panther } \\
\text { (Puma concolor coryi) }\end{array}$ & USA & $-^{\mathrm{b}}$ \\
\hline Identical to AF399930 (Yabsley et al. 2006) & Texas cougar $(P$. c. stanleyana $)$ & USA & $-^{\mathrm{b}}$ \\
\hline Identical to AF399930 (Bondy et al. 2005) & Tick (Amblyomma americanum) & USA & $-^{\mathrm{b}}$ \\
\hline DQ382277 (Unpublished) & Spotted cat (Leopardus tigrinus) & Brazil & LE \\
\hline AY496273 (Luaces et al. 2005) & Iberian lynx (Lynx pardinus) & Spain & IL1 \\
\hline EF094469 (This work) & Iberian lynx (Lynx pardinus) & Spain & IL2 \\
\hline EF094470 (This work) & Iberian lynx (Lynx pardinus) & Spain & IL3 \\
\hline EF094468 (This work) & Iberian lynx (Lynx pardinus) & Spain & IL4 \\
\hline AF531418 (Ketz-Riley et al. 2003) & Pallas cat (Otocolobus manul) & Mongolia & $\mathrm{PC} 1$ \\
\hline AY485690 (Reichard et al. 2005) & Pallas cat (Otocolobus manul) & Mongolia & $\mathrm{PC} 2$ \\
\hline AY485691 (Reichard et al. 2005) & Pallas cat (Otocolobus manul) & Mongolia & PC3 \\
\hline L19080 (Allsopp et al. 1994) & Not reported & USA & SA \\
\hline
\end{tabular}

a GenBank Accession number.

b Sequences identical to AF399930 (DC1).

with a combination of ketamine (Imalgène ${ }^{\circledR}$, Merial, France) and medetomidine (Domtor ${ }^{\circledR}$, Pfizer, Spain). Blood was collected from the brachial vein in tubes with lithium heparin as anticoagulant and stored at $-20{ }^{\circ} \mathrm{C}$.

DNA was extracted from whole blood (400 $\mu \mathrm{l})$ using the ReadyAmp Genomic DNA Purification System (Promega, Madison, WI, USA) according to the manufacturer's instructions.

\section{Polymerase chain reaction $(P C R)$ and sequence analysis}

A 1726-bp region of the $18 \mathrm{~S}$ rRNA gene from members of Piroplasmorida was amplified by PCR using primers 7549 (5'-GTCAGGATCCTGGGTTGATCCTGCCAG-3') and 7548 (5'-GACTGAATTCGACTTCTCCTTCCTTTAAG-3') (Reichard et al. 2005). One $\mu \mathrm{l}$ (1-10 ng) DNA was used with $10 \mathrm{pmol}$ of each primer in a $50 \mu \mathrm{l}$ volume PCR (1.5 mm $\mathrm{MgSO}_{4}, 0 \cdot 2 \mathrm{~mm}$ dNTP, $1 \mathrm{X} \mathrm{AMV} / T f$ reaction buffer, $5 \mathrm{u} T f$ DNA polymerase) employing the Access R'T-PCR system (Promega). Reactions were performed in an automated DNA thermal cycler (Techne model TC-512, Cambridge, England, $\mathrm{UK}$ ) for 35 cycles. After an initial denaturation step of $1 \mathrm{~min}$ at $94{ }^{\circ} \mathrm{C}$, each cycle consisted of a denaturing step of $30 \mathrm{sec}$ at $94{ }^{\circ} \mathrm{C}$, an annealing step for $30 \mathrm{sec}$ at $65{ }^{\circ} \mathrm{C}$ and an extension step of $2 \mathrm{~min}$ at $68^{\circ} \mathrm{C}$. The programme ended by storing the reactions at $10{ }^{\circ} \mathrm{C}$. Negative control reactions were performed with the same procedures, but adding nuclease-free distilled water (Promega) instead of DNA to monitor contamination of the PCR. Positive control reactions were done with $C$. felis DNA, kindly provided by Drs A. Alan Kocan and Mason V. Reichard (Oklahoma
State University, Stillwater, OK, USA; Reichard et al. 2005). PCR products were electrophoresed on $1 \%$ agarose gels to check the size of amplified fragments by comparison to a DNA molecular weight marker (1 Kb DNA Ladder, Promega). Amplified fragments were resin purified (Wizard, Promega) and cloned into the pGEM-T vector (Promega) for sequencing both strands by double-stranded dyetermination cycle sequencing (Secugen SL, Madrid, Spain). At least 2 independent clones were sequenced for each PCR.

Multiple sequence alignment was performed using the programme AlignX (Vector NTI Suite V 5.5, InforMax, North Bethesda, MD, USA) with an engine based on the Clustal $\mathrm{W}$ algorithm (Thompson et al. 1994). BLAST (Altschul et al. 1990) was used to search the NCBI databases to identify previously reported sequences with identity to those obtained in the study described here.

For phylogenetic analysis, nucleotides were coded as unordered, discrete characters with 5 possible character-states: A, C, G, T, or $\mathrm{N}$ and gaps were coded as missing data. The phylogenetic analysis was conducted using Mega version 3.1 (Kumar et al. 2004) and the sequence distance method using the Neighbor-Joining (NJ) algorithm of Saitou and Nei (1987) with Kimura 2 parameters correction. Stability or accuracy of inferred topology(ies) were assessed via bootstrap analysis (Felsenstein, 1985) of 1000 iterations. Cytauxzoon sp. sequences discovered in this study and those reported previously were included in the analysis (Table 2). Characterstate changes for $C$. felis $18 \mathrm{~S}$ rRNA sequences were polarized by designating Theileria equi (GenBank Accession number AY534882) and Babesia gibsoni (AF158702) as outgroups. 
Table 3. Percentage identity among 18S rRNA nucleotide sequences between Cytauxzoon species

(Sequences were aligned and percentage identity/similarity was determined using the program AlignX. Abbreviations are described in Table 1.)

\begin{tabular}{|c|c|c|c|c|c|c|c|c|c|c|c|c|}
\hline & \multicolumn{12}{|c|}{ Percentage sequence identity } \\
\hline & DC1 & DC2 & DC3 & LE & IL1 & IL2 & IL3 & IL4 & PC1 & $\mathrm{PC} 2$ & PC3 & $\mathrm{SA}$ \\
\hline DC1 & 100 & & & & & & & & & & & \\
\hline $\mathrm{DC} 2$ & $99 \cdot 59$ & 100 & & & & & & & & & & \\
\hline DC3 & $95 \cdot 62$ & $95 \cdot 62$ & 100 & & & & & & & & & \\
\hline $\mathrm{LE}$ & $99 \cdot 42$ & $99 \cdot 50$ & $96 \cdot 19$ & 100 & & & & & & & & \\
\hline IL1 & $95 \cdot 49$ & $95 \cdot 37$ & $99 \cdot 11$ & $95 \cdot 77$ & 100 & & & & & & & \\
\hline IL2 & $95 \cdot 85$ & $95 \cdot 79$ & $99 \cdot 13$ & $96 \cdot 68$ & $99 \cdot 40$ & 100 & & & & & & \\
\hline IL3 & $95 \cdot 68$ & $95 \cdot 68$ & $99 \cdot 02$ & $96 \cdot 44$ & $98 \cdot 99$ & $99 \cdot 53$ & 100 & & & & & \\
\hline IL4 & $95 \cdot 56$ & $95 \cdot 56$ & $98 \cdot 90$ & $96 \cdot 44$ & $98 \cdot 99$ & $99 \cdot 42$ & $99 \cdot 76$ & 100 & & & & \\
\hline PC1 & $96 \cdot 33$ & $96 \cdot 33$ & $98 \cdot 71$ & $96 \cdot 35$ & $99 \cdot 16$ & $99 \cdot 48$ & $99 \cdot 74$ & $99 \cdot 48$ & 100 & & & \\
\hline PC2 & $95 \cdot 76$ & $95 \cdot 76$ & $98 \cdot 91$ & $96 \cdot 35$ & $99 \cdot 21$ & $99 \cdot 51$ & $99 \cdot 75$ & $99 \cdot 51$ & 100 & 100 & & \\
\hline PC3 & $95 \cdot 76$ & $95 \cdot 70$ & $98 \cdot 79$ & $96 \cdot 27$ & $99 \cdot 21$ & $99 \cdot 51$ & $99 \cdot 75$ & $99 \cdot 51$ & 100 & 100 & 100 & \\
\hline $\mathrm{SA}$ & $99 \cdot 76$ & $99 \cdot 71$ & $95 \cdot 79$ & $99 \cdot 50$ & $95 \cdot 79$ & $96 \cdot 02$ & $95 \cdot 79$ & $95 \cdot 74$ & $96 \cdot 20$ & 96 & $95 \cdot 94$ & 100 \\
\hline
\end{tabular}

\section{Sequence Accession numbers}

The GenBank Accession numbers for Iberian lynx C. felis 18S rRNA sequences are EF094468EF094470.

\section{RESULTS}

\section{Prevalence of Cytauxzoon spp.}

Only 3 lynxes were found to be infected (Table 1). The overall observed prevalence of Cytauxzoon spp. in Iberian lynx was $15 \%$ (95\% CI: 4-37\%). All the infected lynxes were young males (1 subadult, 2 juveniles) sampled in the early summer of 2006 in Sierra Morena. Thus, the observed prevalence in Sierra Morena was 33\% (95\% CI : 10-68\%). No positive results were obtained in samples from Doñana. Although all the infected individuals were young males (Table 1), we did not find sex, or agerelated differences in the observed prevalence of Cytauxzoon spp.

\section{Molecular characterization of Cytauxzoon spp.}

To characterize the genetic diversity of Cytauxzoon spp. globally, we used the sequences reported in this study and those from Cytauxzoon spp. that have been genetically characterized in different domestic and wild felids and ticks from North and South America, Asia and Europe (Table 2). Three different Cytauxzoon sp. 18S rRNA sequences were obtained from the Iberian lynx studied in this work. These sequences differed from each other in a maximum of $0.6 \%$ nucleotides but diverged in up to $1.0 \%$ with respect to the previously reported sequence of a Cytauxzoon sp. from an Iberian lynx (Luaces et al. 2005) ('Table 3). Highly identical (>99.4\%) $18 \mathrm{~S}$ rRNA sequences were found in $C$. felis from cats, wild felids and ticks in North and South America
(Table 3). However, these sequences diverged in 3-5\% from Asian and European Cytauxzoon spp. sequences, which showed a higher degree of sequence divergence (up to $1 \cdot 3 \%$ ) (Table 3 ).

The phylogenetic analysis of Cytauxzoon spp. using the $18 \mathrm{~S}$ rRNA sequences resulted in 2 welldefined clusters. The Cytauxzoon spp. from Iberian lynx clustered together with organisms obtained from a cat in Spain and Pallas cats in Mongolia (Fig. 1). The second cluster contained C. felis obtained from cats, wild felids and ticks in the United States and Brazil (Fig. 1). The Cytauxzoon sp. from Iberian lynx described here was more closely related to that obtained from the Spanish cat than to the organism previously described in an Iberian lynx, which clustered together with Mongolian Pallas cat C. manul organisms (Fig. 1).

\section{DISCUSSION}

\section{Prevalence of Cytauxzoon $s p p$.}

The primacy of ecological and conservation criteria caused our sample to be age- and sex-biased. Given its conservation status, every capture of a wild Iberian lynx obeyed a very specific purpose. Juvenile lynxes caught in the summer dominated the Sierra Morena sample because this age class was selected to supply the Captive Breeding Program. Adult lynxes were caught in autumn-winter in Doñana because this season was most suitable for concurrent ecological studies.

The prevalence observed in the present study is similar to that reported in bobcats from Oklahoma (United States; Glenn et al. 1982; Kocan et al. 1985). The absence of positive results in samples from Doñana agrees with the previous study of Luaces et al. (2005), who did not detect the piroplasm in any of the 47 samples from this area. 


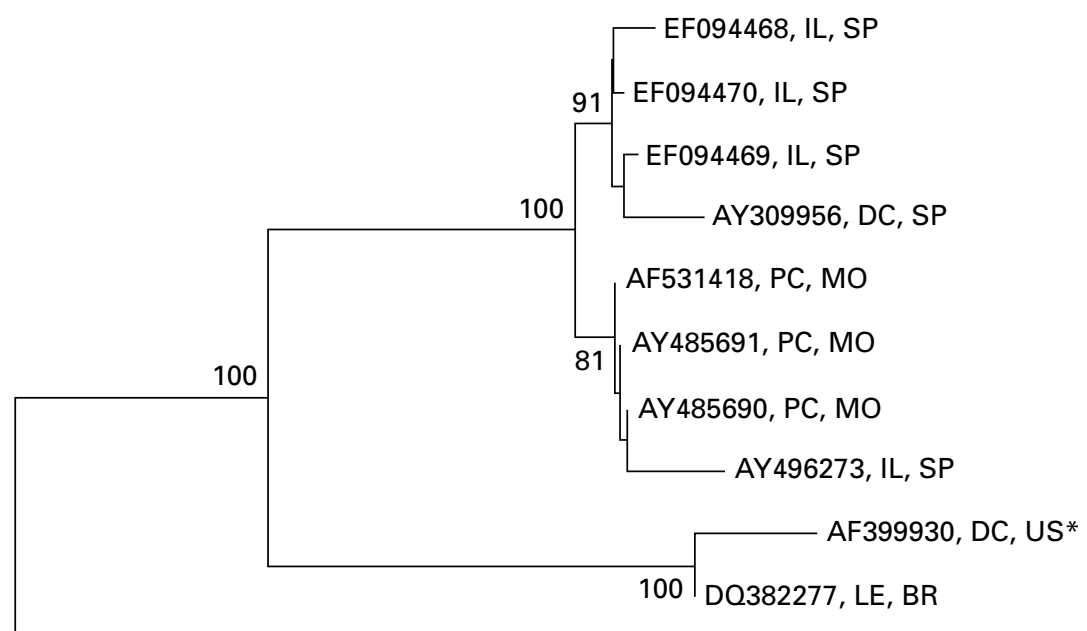

T. equi

B. gibsoni

0.01

Fig. 1. Phylogenetic analysis of Cytauxzoon spp. 18S rRNA sequences based on NJ sequence distance method and 1000 bootstrap iterations. Numbers on branches indicate $>70 \%$ support for each clade. Cytauxzoon spp. are described in Table 1 and are represented as GenBank sequence Accession number, host, location. Abbreviations: IL, Iberian lynx; DC, domestic cat; PC, Pallas cat; LE, leopard; SP, Spain; MO, Mongolia; USA, United States; BR, Brazil. * Sequences identical to AF399930 have been reported in organisms from Florida panther (USA), Texas cougar (USA) and Amblyomma americanum ticks (USA).

The 3 parasitized lynxes were sampled in summer. The lynx analysed by Luaces et al. (2005) was caught in March. In agreement with these findings, Kier and Greene (1998) reported that most cases of cytauxzoonosis in domestic cats in the United States were observed between May and September. Although impossible to analyse in this study, the sampling season may affect the prevalence of Cytauxzoon spp. in Iberian lynx due, among other factors, to the life cycle of the currently unknown tick vector in Spain.

Our results did not determine to what extent the parasite is absent from the Doñana area or whether the infection is only detectable during summer months. Sierra Morena and Doñana Iberian lynx populations could have been functionally connected in the past (Rodríguez and Delibes, 2002). Therefore, the hypothetical absence of Cytauxzoon infections in Doñana would be only possible if the vector tick species is absent from this area or the pathogen has become extinct due to the small population size of the vertebrate host (<50 lynxes; Palomares et al. 1991; Guzmán et al. 2004). The possibility of Iberian lynx parasite species becoming extinct together with their host was already suggested for the host-specific louse, Felicola (Lorisicola) isidoroi (Pérez and Palma, 2001).

\section{Molecular characterization of Cytauxzoon spp.}

Based on sequence analysis, Reichard et al. (2005) proposed a new name, C. manul, for Cytauxzoon sp. found in Pallas cat from Mongolia. The analysis reported here supports the distinction between American and Eurasian Cytauxzoon spp. and suggests that different species or strains may exist in different geographical locations. The results described here also suggest that at least 2 different Cytauxzoon species or strains may infect Iberian lynx in Spain, 1 closely related to $C$. manul, and a new species described here and different from $C$.felis and C. manul. However, further analyses with more Cytauxzoon strains will be required to fully address this question.

On the basis of $18 \mathrm{~S}$ rRNA gene sequences analysed in the present study, the $C$. felis strains responsible for deaths among cats (Meinkoth and Kocan, 2005) and presumably in bobcats, the natural reservoir host (Nietfeld and Pollock, 2002) in the United States are not genetically distinct from the other American C. felis strains that have been obtained and sequenced from non-fatal cases. However, in some instances rRNA sequence analyses cannot differentiate closely related species, subspecies or strains (Fox et al. 1992). Therefore, it is possible that Cytauxzoon spp. strains with different virulence exist but their discrimination may require the use of different gene sequences for analysis.

In conclusion, the present study showed that (i) infections with Cytauxzoon spp. occur in wild Iberian lynx, (ii) the pathogen could be absent from one of the last two lynx metapopulations, and iii) the sequences detected in Iberian lynx are genetically 
variable and may represent 2 different Cytauxzoon species or strains.

Cytauxzoon felis causes fatal infections in wild bobcat (Nietfeld and Pollock, 2002) and at least 1 exotic felid, a white tiger, died of cytauxzoonosis in the United States (Garner et al. 1996). These facts reinforce the threat for fatal Cytauxzoon infections in Iberian lynx. Disease risks must be taken into account in the Iberian lynx management strategies, e.g. if translocations or re-introductions are carried out. Coexistence with domestic or feral cats might be an additional source of infection.

The characterization of the genetic diversity in Cytauxzoon spp. isolated from fatal and non-fatal cases of cytauxzoonosis in different feline species and regions of the world may contribute to the understanding of the phylogeny and pathogenicity of different species/strains of the organism and the potential risk for endangered species.

This work is dedicated to Dr A. Alan Kocan $†$ (Oklahoma State University, Stillwater, OK, USA). This is a contribution to the 'Programa de Actuaciones para la Conservación del Lince en Andalucía II', Consejería de Medio Ambiente, Junta de Andalucía (CMA). We wish to thank M. A. Simón, R. Cadenas, and the field personnel of CMA; J. V. López-Bao, M. Viota, J. C. Rivilla, F. Palomares and M. Delibes from Estación Biológica de Doñana; F. Martínez and A. Vargas from Iberian Lynx Captive Breeding Program. V. Naranjo was funded by Junta de Comunidades de Castilla - La Mancha, Spain. A. Rodríguez was supported by Consejería de Innovación, Ciencia y Empresa, Junta de Andalucía, Spain.

\section{REFERENCES}

Allsopp, M. T., Cavalier-Smith, T., De Waal, D. T. and Allsopp, B. A. (1994). Phylogeny and evolution of the piroplasms. Parasitology 108, 147-152.

Altschul, S. F., Gish, W., Miller, W., Myers, E. W. and Lipman, D. J. (1990). Basic local alignment search tool. Fournal of Molecular Biology 215, 403-410.

Bondy P. J. Jr., Cohn, L. A., Tyler, J. W. and Marsh, A. E. (2005). Polymerase chain reaction detection of Cytauxzoon felis from field-collected ticks and sequence analysis of the small subunit and internal transcribed spacer 1 region of the ribosomal RNA gene. Fournal of Parasitology 91, 458-461.

Birkenheuer, A. J., Le, J. A., Valenzisi, A. M., Tucker, M. D., Levy, M. G. and Breitschwerdt, E. B. (2006a). Cytauxzoon felis infection in cats in the mid-Atlantic states: 34 cases (1998-2004). Fournal of the American Veterinary Medicine Association 228, 568-571.

Birkenheuer, A. J., Marr, H., Alleman, A. R., Levy, M. G. and Breitschwerdt, E. B. $(2006 b)$. Development and evaluation of a PCR assay for the detection of Cytauxzoon felis DNA in feline blood samples. Veterinary Parasitology 137, 144-149.

Blouin, E. F., Kocan, A. A., Kocan, K. M. and Hair, J. (1987). Evidence of a limited schizogonous cycle for Cytauxzoon felis in bobcats following exposure to infected ticks. Fournal of Wildlife Diseases 23, 499-501.
Criado-Fornelio, A., González del Río, M. A., BulingSaraña, A. and Barba-Carretero, J. C. (2004). The "expanding universe" of piroplasms. Veterinary Parasitology 119, 337-345.

de Castro, F. and Bolker, B. (2005). Mechanisms of disease-induced extinction. Ecology Letters 8, 117-126.

Deem, S. L., Karesh, W. B. and Weisman, W. (2001). Putting theory into practice: wildlife health in conservation. Conservation Biology 15, 1224-1233.

Felsenstein, J. (1985). Confidence limits on phylogenies: an approach using the bootstrap. Evolution 39, 783-791.

Ferreras, P., Delibes, M., Palomares, F., Fedriani, J. M., Calzada, J. and Revilla, E. (2004). Dispersal in the Iberian lynx: factors affecting the start, duration, distance and dispersal success. Behavioral Ecology 15, $31-40$.

Forrester, D. J. (1992). Parasites and Diseases of Wild Mammals in Florida. University Press of Florida, Gainesville, Florida.

Fox, G. E., Wisotzkey, J. D. and Jurtshuk P. Jr. (1992). How close is close: $16 \mathrm{~S}$ rRNA sequence identity may not be sufficient to guarantee species identity. International Fournal of Systematic Bacteriology 42, 166-170.

Garner, M. M., Lung, N. P., Citino, S., Greiner, E. C., Harvey, J. W. and Homer, B. L. (1996). Fatal cytauxzoonosis in a captive-reared white tiger (Panthera tigris). Veterinary Pathology 33, 82-86.

Glenn, B. L., Rolley, R. E. and Kocan, A. A. (1982). Cytauxzoon-like piroplasms in erythrocytes of wildtrapped bobcats in Oklahoma. Fournal of the American Veterinary Medical Association 181, 1251-1253.

Guzmán, J. N., García, F. J., Garrote, G., Pérez de Ayala, R. and Iglesias, C. (2004). El Lince ibérico (Lynx pardinus) en España y Portugal. Censo-diagnóstico de sus Poblaciones. Dirección General para la Biodiversidad, Ministerio de Medio Ambiente, Madrid.

Haydon, D. T., Laurenson, M. K. and Sillero-Zubiri, C. (2002). Integrating epidemiology into population viability analysis: managing the risk posed by rabies and canine distemper to the Ethiopian wolf. Conservation Biology 16, 1372-1385.

Ketz-Riley, C. J., Reichard, M. V., Van den Bussche, R. A., Hoover, J. P., Meinkoth, J. and Kocan, A. A. (2003). An intraerythrocytic small piroplasm in wildcaught Pallas's cats (Otocolobus manul) from Mongolia. Fournal of Wildlife Diseases 39, 424-430.

Kier, A. B. and Greene, C. E. (1998). Cytauxzoonosis. In Infectious Diseases of Dog and Cat (ed. Greene, C. E.), pp. 517-519. W.B. Saunders Company, Pennsylvania, USA.

Kier, A. B., Wightman, S. R. and Wagner, J. E. (1982). Interspecies transmission of Cytauxzoon felis. American Fournal of Veterinary Research 43, 102-105.

Kocan, A. A., Blouin, E. F. and Glenn, B. L. (1985). Hematologic and serum chemical values for free-ranging bobcats, Felis rufus (Schreber), with reference to animals with natural infections of Cytauxzoon felis Kier, 1979. Fournal of Wildlife Diseases 21, 190-192.

Kumar, S., Tamura, K. and Nei, M. (2004). MEGA3: Integrated software for Molecular Evolutionary Genetics Analysis and sequence alignment. Briefings in Bioinformatics 5, 150-163. 
Luaces, I., Aguirre, E., García-Montijano, M., Velarde, J., Tesouro, M. A., Sánchez, C., Galka, M., Fernández, P. and Sainz, A. (2005). First report of an intraerythrocytic small piroplasm in wild Iberian lynx (Lynx pardinus). Fournal of Wildlife Diseases 41, 810-815.

Mathews, F., Moro, D., Strachan, R., Gelling, M. and Buller, N. (2006). Health surveillance in wildlife reintroductions. Biological Conservation 131, 338-347.

Meinkoth, J. H. and Kocan, A. A. (2005). Feline cytauxzoonosis. Veterinary Clinics of North America: Small Animal Practice 35, 89-101.

Meinkoth, J., Kocan, A. A., Whitworth, L., Murphy, G., Fox, J. C. and Woods, J. P. (2000). Cats surviving natural infection with Cytauxzoon felis: 18 cases (1997-1998). Fournal of Veterinary Internal Medicine 14, 521-525.

Nietfeld, J. C. and Pollock, C. (2002). Fatal cytauxzoonosis in a free-ranging bobcat (Lynx rufus). Fournal of Wildlife Diseases 38, 607-610.

Nowell, K. and Jackson, P. (1996). Wild Cats : Status Survey and Conservation Action Plan. IUCN, Gland, Switzerland.

Palomares, F., Rodríguez, A., Laffitte, R. and Delibes, M. (1991). The status and distribution of the Iberian lynx Felis pardina (Temminck) in Coto Doñana area, SW Spain. Biological Conservation 57, 159-169.

Pérez, J. M. and Palma, R. L. (2001). A new species of Felicola (Phthiraptera: Trichodectidae) from the endangered Iberian lynx: another reason to ensure its survival. Biodiversity and Conservation 10, 929-937.

Reichard, M. V., Van den Bussche, R. A., Meinkoth, J. H., Hoover, J. P. and Kocan, A. A. (2005). A new species of Cytauxzoon from Pallas' cats caught in Mongolia and comments on the systematics and taxonomy of piroplasmids. Fournal of Parasitology $\mathbf{9 1}$, 420-426.

Rodríguez, A. and Delibes, M. (2002). Internal structure and patterns of contraction in the geographic range of the Iberian lynx. Ecography 25, 314-328.

Rotstein, D. S., Taylor, S. K., Harvey, J. W. and Bean, J. (1999). Hematologic effects of cytauxzoonosis in Florida panthers and Texas cougars in Florida. Fournal of Wildlife Diseases 35, 613-617.

Saitou, N. and Nei, M. (1987). The neighbor-joining method: a new method for reconstructing phylogenetic trees. Molecular Biology and Evolution 4, 406-425.

Scott, M. E. (1988). The impact of infectious disease on animal populations: implications for conservation biology. Conservation Biology 2, 40-65.

Smith, K. F., Sax, D. F. and Lafferty, K. D. (2006). Evidence for the role of infectious disease in species extinction and endangerment. Conservation Biology 20, 1349-1357.

Thompson, J. D., Higgins, D. G. and Gibson, T. J. (1994). CLUSTAL W : improving the sensitivity of progressive multiple sequence alignment through sequence weighting, positions-specific gap penalties and weight matrix choice. Nucleic Acids Research 22, 4673-4680.

Thorne, E. T. and Williams, E. S. (1988). Disease and endangered species: the black-footed ferret as a recent example. Conservation Biology 2, 66-74.

Yabsley, M. J., Murphy, S. M. and Cunningham, M. W. (2006). Molecular detection and characterization of Cytauxzoon felis and a Babesia species in cougars from Florida. Fournal of Wildlife Diseases 42, 366-374. 